SILVEIRA, E. et al. Perfil clínico, hematológico, anatomopatológico e parasitário na infecção por Rangelia vitalii em cão: relato de caso. PUBVET, Londrina, V. 8, N. 19, Ed. 268, Art. 1784, Outubro, 2014.

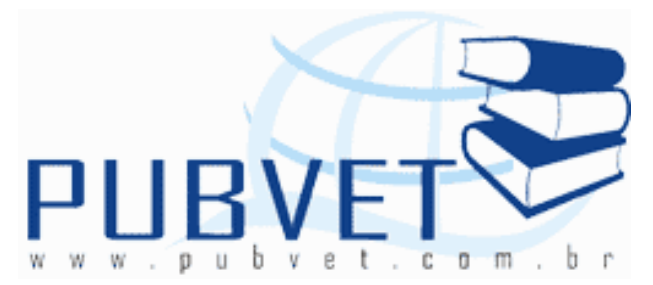

PUBVET, Publicações em Medicina Veterinária e Zootecnia.

\title{
Perfil clínico, hematológico, anatomopatológico e parasitário na infecção por Rangelia vitalii em cão: relato de caso
}

\author{
Elissandra da Silveira ${ }^{1}$, Luciana de Almeida Lacerda² ${ }^{2}$ Ana Elize Ribeiro D'Avila ${ }^{3}$, \\ Sandra Márcia Tietz Marques ${ }^{4}$ \\ ${ }^{1}$ Médica Veterinária, Residente no Hospital de Clínicas Veterinárias da ULBRA \\ 2 Médica Veterinária, Dra., autônoma \\ 3 Médica Veterinária, Especialista em Patologia Clínica Veterinária \\ 4 Médica Veterinária, PhD, Departamento de Patologia Clínica Veterinária, \\ Faculdade de Veterinária - UFRGS. E-mail:smtmuni@hotmail.com
}

\section{Resumo}

O presente relato descreve um caso clínico de rangeliose em cão. A condição clínica, os procedimentos que culminaram com o diagnóstico e o tratamento instituído são abordados.

Palavras-chave: Rangelia vitalii, Apicomplexa, rangeliose canina, diagnóstico. 
SILVEIRA, E. et al. Perfil clínico, hematológico, anatomopatológico e parasitário na infecção por Rangelia vitalii em cão: relato de caso. PUBVET, Londrina, V. 8, N. 19, Ed. 268, Art. 1784, Outubro, 2014.

\title{
Clinical, hematological, parasitological and pathoanatomical profiles of Rangelia vitalii infection in a dog: a case report
}

\begin{abstract}
The present report describes a clinical case of Rangelia vitalii infection in a dog. The clinical status, procedures that led to the diagnosis, and treatment are discussed.
\end{abstract}

Keywords: Rangelia vitalii, Apicomplexa, canine rangeliosis, diagnosis.

\section{Introdução}

A rangeliose canina é uma parasitose sistêmica caracterizada por anemia, icterícia, febre, esplenomegalia, linfadenomegalia, vômitos, hemorragias ao longo do trato gastrintestinal e por sangramentos persistentes na superfície auricular, na cavidade nasal e oral (FRANÇA, 2010; FIGHERA, 2010). Rangelia vitalii foi descrito pela primeira vez por Pestana (1910) e reavaliado por Carine e Maciel (1914), porém recentemente foi validado por técnicas moleculares (SOARES et al., 2011).

Cães de áreas rurais e urbanas podem apresentar o parasitismo associado à infestação por carrapatos das espécies Rhipicephalus sanguineus e Amblyomma aureolatum. O ciclo de vida deste protozoário consiste no estágio de desenvolvimento eritrocítico e na forma exoeritrocitária, ocorrendo no citoplasma de neutrófilos, monócitos e células endoteliais (FHIGERA et al., 2010; SOARES et al., 2011; DA SILVA et al., 2011). Na fase aguda da doença são encontrados principalmente no sangue circulante e encontrados, também, em corte histológico de fígado, baço, pulmão, rim e medula óssea (LORETTI; BARROS, 2005). O agente etiológico pode ser facilmente encontrado, pois ocorre em grande quantidade na maioria dos tecidos, principalmente nos linfonodos, no baço, na medula óssea, no coração e nas tonsilas (FHIGERA et al., 2010). 
SILVEIRA, E. et al. Perfil clínico, hematológico, anatomopatológico e parasitário na infecção por Rangelia vitalii em cão: relato de caso. PUBVET, Londrina, V. 8, N. 19, Ed. 268, Art. 1784, Outubro, 2014.

No diagnóstico diferencial da infecção por Rangelia vitalii devem ser incluídas as doenças infecciosas e parasitárias que ocorrem em cães no Brasil e que partilham a mesma sintomatologia, entre elas, babesiose, ehrlichiose, leishmaniose e leptospirose (LORETTI; BARROS, 2005) e conforme Costa et al. (2012) existem poucos estudos sobre as alterações bioquímicas em cães infectados com R. vitalii, o que motivou esta investigação. Conforme DantasTorres e Otranto (2014) Rangelia vitalii em cães é pouco conhecida da maioria dos veterinários clínicos no Brasil.

O presente relato descreve a condição clínica e os resultados dos exames complementares causados pelo parasitismo por Rangelia vitalii em um cão oriundo do município de Porto Alegre, Rio Grande do Sul.

\section{Relato do caso}

Um cão macho, raça mista, 11 anos de idade, pesando $26 \mathrm{~kg}$, foi atendido no Hospital de Clínicas Veterinárias da Universidade Federal do Rio Grande do Sul (HCV-UFRGS). O proprietário relatou que o animal apresentava epistaxe, sangramento na ponta das orelhas e diarréia sanguinolenta há aproximadamente 10 dias. O cão não era vacinado, apresentava histórico de pulgas e carrapatos, hiporexia, hipodipsia e prostração. Ao exame físico apresentava apatia, desidratação moderada (8\%), índice de escore corporal de caquético a magro (KRONFELD et al., 1991), mucosa oral e ocular hipocoradas e discretamente ictéricas.

A conduta médica recomendada ao proprietário foi de internação do cão. O animal deu baixa no setor de hospitalização e o clínico acompanhou o cão durante todo este período. Diante do diagnóstico presuntivo de infecção piroplásmica, instituiu-se fluidoterapia intravenosa com solução fisiológica ( $\mathrm{NaCl}$ 0,9\%, 1 L, IV) e administração de antimicrobiano (Doxiciclina, 5 mg/kg, IV, BID), dipropionato de imidocarb (5 mg/ $\mathrm{kg}, \mathrm{SC}$, SID) e corticosteróide (dexametasona, $2 \mathrm{mg} / \mathrm{kg}$, IV, SID). 
SILVEIRA, E. et al. Perfil clínico, hematológico, anatomopatológico e parasitário na infecção por Rangelia vitalii em cão: relato de caso. PUBVET, Londrina, V. 8, N. 19, Ed. 268, Art. 1784, Outubro, 2014.

Durante o período de consulta e internação foram realizados os seguintes procedimentos:

1. Amostra de sangue foi coletada por punção venosa. Uma fração foi colocada em tubo contendo EDTA- $\mathrm{K}_{2}$ (ácido etileno-diamino-tetracético dipotássico) para realização do hemograma; outra em tubo seco com ativador de coágulo para obtenção do soro e realização de provas bioquímicas; outra fração foi utilizada para a confecção de esfregaço sanguíneo, corado pelo Panótico rápido (Panotico Rápido LB Laborclin $®$ ) para pesquisa do protozoário (HOFFMANN, 1989).

2. Uma amostra de urina foi coletada através de cateterização para realização da urinálise.

Durante quatro dias o cão permaneceu internado e o quadro clínico evoluiu para o óbito. Com o consentimento formal da proprietária, o animal foi encaminhado para o Setor de Patologia Clínica da FAVET/UFRGS. Foram executadas a necropsia e análise de material biológico por histopatologia.

O exame hematológico revelou um quadro de anemia regenerativa macrocítica hipocrômica acompanhada de leucocitose por neutrofilia com desvio neutrofílico à esquerda regenerativo e monocitose. Na avaliação da morfologia celular, foram observados neutrófilos tóxicos $(1+)$, policromasia e anisocitose discretas nos eritrócitos (Tabela 1).

$\mathrm{Na}$ bioquímica sanguínea, foi detectado aumento discreto da atividade da fosfatase alcalina (FA), aumento do nível de uréia, hipoproteinemia $(36,4 \mathrm{~g} / \mathrm{L})$ e hipoalbuminemia $(10,8 \mathrm{~g} / \mathrm{L})$. A Tabela 2 mostra o resultado da bioquímica sanguínea apresentada pelo cão portador de Rangelia vitalii. 
SILVEIRA, E. et al. Perfil clínico, hematológico, anatomopatológico e parasitário na infecção por Rangelia vitalii em cão: relato de caso. PUBVET, Londrina, V. 8, N. 19, Ed. 268, Art. 1784, Outubro, 2014.

Tabela 1. Parâmetros hematológicos do cão positivo para Rangelia vitalii

\begin{tabular}{llll}
\hline Parâmetro & Amostra & $\begin{array}{l}\text { Referência } \\
\text { (TRALL, 2007) }\end{array}$ & Unidade \\
& & & \\
Eritrócitos & 0,89 & 5,5 a 8,5 & x10 $/ \mathrm{uL}$ \\
Hematócrito & 9 & 37 a 55 & $\%$ \\
Hemoglobina & 2,4 & 12 a 18 & $\mathrm{~g} / \mathrm{dL}$ \\
VCM & 101,1 & 60 a 77 & $\mathrm{fL}$ \\
CHCM & 26,7 & 32 a 36 & $\%$ \\
RDW & 22 & 14 a 17 & $\%$ \\
Plaquetas & 279 & 200 a 500 & $\mathrm{x} 10^{3} / \mathrm{uL}$ \\
Reticulócitos & 7,5 & 0 a 1,5 & $\%$ \\
Leucócitos totais & 58.800 & 6.000 a 17.000 & $/ \mathrm{uL}$ \\
Neutr. Metamielócitos & 588 & 0 & $/ \mathrm{uL}$ \\
Neutr. Bastonetes & 4.704 & 0 a 300 & $/ \mathrm{uL}$ \\
Neutr. Segmentados & 45.276 & 3.000 a 11.500 & $/ \mathrm{uL}$ \\
Basófilos & 0 & 0 & $/ \mathrm{uL}$ \\
Eosinófilos & 0 & 100 a 1.250 & $/ \mathrm{uL}$ \\
Monócitos & 4.704 & 150 a 1.350 & $/ \mathrm{uL}$ \\
Linfócitos & 3.528 & 1.000 a 4.800 & $/ \mathrm{uL}$ \\
\hline VCM: volume corpuscular médio; CHCM: concentração de hemoglobina corpuscular média; \\
RDW: amplitude de distribuição do tamanho dos eritrócitos.
\end{tabular}

Tabela 2. Parâmetros bioquímicos do cão positivo para Rangelia vitalii

\begin{tabular}{lccc}
\hline & \multicolumn{3}{c}{ BIOQUÍMICA SÉRICA } \\
\hline Parâmetro & Amostra & $\begin{array}{c}\text { Referência } \\
\text { (TRALL,2007) }\end{array}$ & Unidade \\
\hline Proteínas totais & 36,4 & 54 a 71 & $\mathrm{~g} / \mathrm{L}$ \\
Albumina & 10,8 & 26 a 33 & $\mathrm{~g} / \mathrm{L}$ \\
\hline
\end{tabular}


SILVEIRA, E. et al. Perfil clínico, hematológico, anatomopatológico e parasitário na infecção por Rangelia vitalii em cão: relato de caso. PUBVET, Londrina, V. 8, N. 19, Ed. 268, Art. 1784, Outubro, 2014.

$\mathrm{Na}$ urinálise foi observada a presença de cetonúria leve (1+), bilirrubinúria moderada $(2+)$, proteinúria moderada $(100 \mathrm{mg} / \mathrm{dL})$, quantidade moderada de cilindros granulosos, bacteriúria severa e piúria moderada.

$\mathrm{Na}$ avaliação do esfregaço sanguíneo, foram observadas inclusões no citoplasma de monócitos compatíveis com a descrição de Rangelia vitalii (SOARES et al., 2011) (Figuras 1A e 1B).

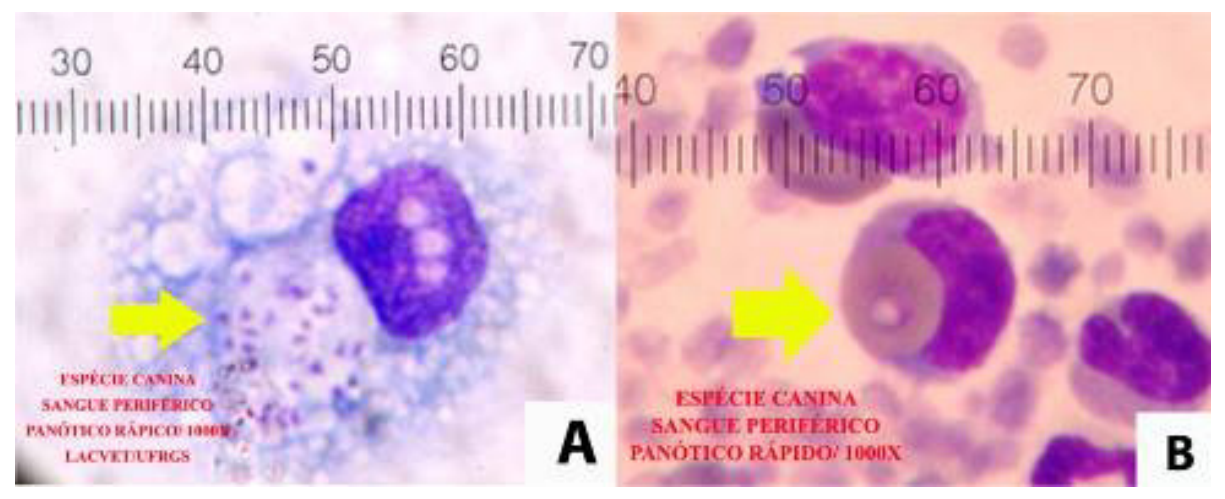

Figura 1. A: Esquizontes de Rangelia vitalii no interior de monócito; B: Trofozoíto de R. vitalii em eritrócito fagocitado por monócito. (Panótico Rápido/ 1000x).

$\mathrm{Na}$ necropsia, dentre as alterações macroscópicas relevantes estavam dilatação cardíaca bilateral e edema de membros torácicos. O exame histopatológico permitiu a visualização de formas parasitárias entre os cardiomiócitos condizentes com o protozoário Rangelia vitalii bem como focos de miocardite mista discreta no coração.

\section{Discussão}

A evolução ao óbito decorrente da patogênese da rangeliose, doença imunomediada, hemolítica e extravascular, descrita neste relato denota a característica grave desta enfermidade e se assemelha ao estudo de Fhigera et al. (2010) com 35 cães portadores de $R$. vitalii estudados após a morte.

A avaliação de múltiplos parâmetros clínicos e de exames complementares são fundamentais para se fazer o diagnóstico diferencial entre rangeliose e outras doenças que cursam com sintomatologia semelhante. 
SILVEIRA, E. et al. Perfil clínico, hematológico, anatomopatológico e parasitário na infecção por Rangelia vitalii em cão: relato de caso. PUBVET, Londrina, V. 8, N. 19, Ed. 268, Art. 1784, Outubro, 2014.

Na bioquímica sanguínea deste cão foi detectado aumento discreto da atividade da fosfatase alcalina, aumento do nível de uréia, hipoproteinemia $(36,4 \mathrm{~g} / \mathrm{L})$ e hipoalbuminemia $(10,8 \mathrm{~g} / \mathrm{L})$. A diminuição na concentração das proteínas totais observada pode ocorrer em casos de falha hepática, transtornos intestinais e renais, hemorragia ou por deficiência alimentar. Neste caso o cão estava enfermo a cerca de 10 dias, sem apetite e com emagrecimento progressivo, corroborando com os achados bioquímicos. Um estudo de Da Silva et al. (2011), para detectar parâmetros do perfil bioquímico infectaram, experimentalmente, cães com $R$. vitalii e avaliaram as alterações bioquímicas na fase aguda da infecção e concluíram que houve alteração no perfil bioquímico, com aumento na alanina aminotrasferase, creatinina quinase e aspartato aminotransferase, porém não foram observadas alterações séricas na gama-glutamiltransferase, uréia e creatinina. Diferentemente de Da Silva et al. (2011), o cão deste relato mostrou aumento da concentração de uréia, que pode estar relacionado com aumento do catabolismo protéico devido ao déficit energético e por desidratação.

O resultado obtido na urinálise foi compatível com um quadro de lipomobilização decorrente da diminuição da ingestão de alimentos ou jejum prolongado, hepatopatia ou doença hemolítica, além de cistite, com suspeita de danos degenerativos tubulares (LORETTI; BARROS, 2004; THRALL, 2007).

A fosfatase alcalina, embora de função inespecífica, está amplamente distribuída nos tecidos. Como esta enzima está localizada nas membranas de revestimento dos canalículos biliares, ela está elevada nas desordens do trato biliar, ocasionado pelo impedimento do fluxo biliar, podendo atingir até 2-3 vezes o valor de referência (LORETTI; BARROS, 2004; THRALL, 2007), compatível com o resultado diagnóstico deste relato.

Os achados hematológicos são sugestivos de um processo inflamatório, reforçando a possibilidade da presença de um fator imunomediado induzindo um quadro de hemólise extra-vascular, que juntamente com o sangramento colabora para o quadro de anemia observado neste paciente e descrito por 
SILVEIRA, E. et al. Perfil clínico, hematológico, anatomopatológico e parasitário na infecção por Rangelia vitalii em cão: relato de caso. PUBVET, Londrina, V. 8, N. 19, Ed. 268, Art. 1784, Outubro, 2014.

outros autores como o achado mais frequente (LORETTI; BARROS, 2004; FHIGERA et al., 2010; FRANÇA, 2010; COSTA et al., 2012).

Publicações sobre $R$. vitalii descrevem a presença do parasito em esfregaços sanguíneos onde ele é visto no interior dos eritrócitos ou livre no sangue circulante. Todavia, há pesquisadores que não têm encontrado o protozoário em esfregaços sanguíneos, mas apenas em cortes histológicos (GONZÁLEZ; SILVA, 2006; MOREIRA et al., 2013), entretanto, neste trabalho $R$. vitalii foi observada em células sanguíneas e no miocárdio, detectado também por Fhigera et al. (2010).

O tratamento da infecção por $R$. vitalii inclui a administração de doxiciclina e dipropionato de imidocarb, além de corticoterapia, a qual tem apresentado bons resultados no tratamento da anemia hemolítica imunomediada. Quando necessário, transfusão sanguínea e fluidoterapia também são adicionadas ao protocolo de tratamento (LORETTI et al., 2003; FRANÇA, 2010).

A conduta terapêutica foi executada segundo preceitos padrões norteados pela suspeita de infecção parasitária, imediatamente após a coleta de material biológico para exames complementares confirmatórios.

Conforme DANTAS-TORRES (2008) e DANTAS-TORRES e OTRANTO (2014) é importante o entendimento de que $R$. vitalii, aparentemente, é de ocorrência comum porém restrita às regiões sul e sudeste do Brasil, bem como o diagnóstico ser confundido com babesiose e ehrliquiose, deixando a indicação da importância de ferramentas diagnósticas para se detectar o agente causal e identificar o vetor presente na região de ocorrência de casos de rangeliose.

\section{Conclusão}

O resultado da leitura do esfregaço sanguíneo confirmou a presença de esquizontes e trofozoitos de $R$. vitalii no miocárdio. $O$ tratamento se estendeu até que, infelizmente, o cão evoluiu para o óbito, porém houve a chance de expandir o estudo deste caso, através das técnicas diagnósticas histopatológicas. 
SILVEIRA, E. et al. Perfil clínico, hematológico, anatomopatológico e parasitário na infecção por Rangelia vitalii em cão: relato de caso. PUBVET, Londrina, V. 8, N. 19, Ed. 268, Art. 1784, Outubro, 2014.

\section{Agradecimento}

À proprietária do animal, que diante da perda de seu animal de estimação, entendeu o propósito deste estudo e doou seu cão para que a equipe pudesse aprofundar a investigação.

\section{Referências}

CARINI, A.; MACIEL, J. Sobre a moléstia dos cães, chamada Nambiuvú, e o seu parasita (Rangelia vitalii). Anais Paulista de Medicina e Cirurgia, 1914; 3:65-71.

COSTA, M. M. et al. Rangelia vitalii: changes in the enzymes ALT, CK and AST during the acute phase of experimental infection in dogs. Revista Brasileira de Parasitologia Veterinária, 2012; 21(3): 243-248.

DANTAS-TORRES, F. 2008. Canine vector-borne diseases in Brazil. Parasite \& Vectors, $1: 25$. DOI:10.1186/1756-3305-1-25

DANTAS-TORRES, F.; OTRANTO, D. Dogs, cats, parasites, and humans in Brazil: opening the black box. Parasites \& Vectors, 2014, 7(22):1-25.

DA SILVA, A. S. et al. Experimental infection with Rangelia vitalii in dogs: Acute phase, parasitemia, biological cycle, clinical-pathological aspects and treatment. Experimental Parasitology 2011; 128(4): 347-352.

FRANÇA, R. T. Rangelia vitalii in dogs in southern Brazil. Comparative Clinical Pathology 2010; 19:383-7.

FIGHERA, R. et al. 2010. Patogênese e achados clínicos, hematológicos e anatomopatológicos da infecção por Rangelia vitalii em 35 cães (1985-2009). Pesquisa Veterinária Brasileira, 30:974-87.

GONZÁLEZ, F. H. D.; SILVA, S. C. Introdução à bioquímica clínica veterinária. 2.ed. Porto Alegre: Ed. UFRGS; 2006.

HOFFMANN, R. P. Diagnóstico de parasitismo veterinário. Sulina: Porto Alegre. 1989. $156 \mathrm{p}$.

KRONFELD, D. S. et al. Body condition and energy intakes of dogs in a referral teaching hospital. Journal of Nutrition 1991; 121:S157-S158.

LORETTI, A. P. et al. Parasitism of dogs by Rangelia vitalii in southern Brazil: clinical, pathological and ultrastructural study. Enapave-Encontro Nacional de Patologia Veterinária, Botucatu, SP, FMVZ,UNESP, 2003; 11:178.

LORETTI, A. P.; BARROS, S. S. Parasitismo por Rangelia vitalli em cães ("nambiuvú", "peste de sangue") - uma revisão crítica sobre o assunto. Arquivos do Instituto Biológico 2004; $1: 101-131$.

LORETTI, A. P.; BARROS, S. S. Hemorrhagic disease in dogs infected with an unclassified intraendothelial piroplasm in southern Brazil. Veterinary Parasitology 2005; 134:193-213. 
MOREIRA, M. V. L. et al. Infecção por Rangelia vitalii em um cão em Minas Gerais. In: XVI Encontro Nacional de Patologia Veterinária, XVI ENAPAVE, VI Simpósio Brasileiro da CL Davis Foundation. 2013. Anais .... Resumo KK16. Disponível em: < http://www.enapave.com.br/anais/pdf/KK16.pdf>. Acesso em: 28/02/2014.

PESTANA BR. O nambiuvú. Revista de Medicina, São Paulo 1910; 22:423-426.

SOARES, J. F. et al. Detection and molecular characterization of a canine piroplasm from Brazil. Veterinary Parasitology 2011; 180:203-208.

THRALL, M. A. Hematologia e bioquímica clínica veterinária. São Paulo: Ed. Roca, 2007. cap. 8, p. 92-96. 